\title{
Kit Fine on Tense and Reality
}

\author{
Steven Savitt \\ University of British Columbia \\ Department of Philosophy \\ Vancouver, British Columbia \\ Canada \\ savitt01@gmail.com
}

Article info

CDD: 115

Received: 13.11.2016; Accepted: 17.11.2016

DOI: http://dx.doi.org/10.1590/0100-6045.2016.V39N4.SS

Keywords:

Ontology of Time

Fragmentalism

Kit Fine

Mc'Taggart

\section{ABSTRACT}

Kit Fine $(2005,2006)$ recently described and defended a novel position in the philosophy of time, fragmentalism. It is not often that a new (and even perhaps a radically new) option appears in this old field, and for that reason alone these two essays merit serious attention. I will try to present briefly but fairly some of the considerations that Fine thinks favour fragmentalism. I will also weigh the merits of fragmentalism against the view that Fine presents as its chief rival, relativism, as well as the merits of both against the view that he calls antirealism. Along the way, we should pick up a clearer picture of fragmentalism itself.

Kit Fine $(2005,2006)$ recently described and defended a novel position in the philosophy of time, fragmentalism. ${ }^{1}$ This view, as he sees it, is

$\ldots$ a radically new idea. There are to be many alternative realities. But these are not alternative possibilities for reality, for no one of them is

${ }^{1}$ Fine (2005) is the more detailed presentation of his argument. Fine (2006) is much briefer and presents what I assume Fine took to be essential. Page references to Fine's papers that contain no date will be to Fine (2005).

Manuscrito - Rev. Int. Fil. Campinas, v. 39, n. 4, pp. 75- 99, out.dez: 2016. 
distinguished as actual. Nor are they alternative perspectives on reality, for there is no more fundamental reality upon which they are a perspective. And nor are they incomplete parts of a more comprehensive reality, since each of them, on its own, settles all of the facts. We might say, if we like, that reality as a whole 'manifests' itself in these different ways, that it becomes 'alive' or vivid' through certain realities holding rather than others. But in saying this we must recognize that there is no underlying reality, of the usual sort, of which these different realities are a manifestation. The differential manifestation of how things are is itself integral to the very character of reality. $(2006,403)$

It is not often that a new (and even perhaps a radically new) option appears in this old field, and for that reason alone these two essays merit serious attention. I will try to present briefly but fairly some of the considerations that Fine thinks favour fragmentalism. I will also weigh the merits of fragmentalism against the view that Fine presents as its chief rival, relativism, as well as the merits of both against the view that he calls anti-realism. Along the way, we should pick up a clearer picture of fragmentalism itself.

Fine's discussion is a rich stew of definitions, distinctions, and arguments. In order to present and evaluate what I consider the main thread of Fine's discussion of time in a reasonable space, I will have to omit much that others may find of interest.

\section{The Neo-McTaggartian Argument ${ }^{2}$}

The conceptual stage for Fine's views is set and the actors on it constrained by an argument that Fine says can be "loosely traced" (2006, 399) back to the infamous argument of McTaggart (1908). Fine's purposes, however, are quite different from McTaggart's. McTaggart's argument was intended to prove that time is unreal. Fine's argument is intended to show

\footnotetext{
${ }^{2}$ The version of the argument I present Fine calls simple McTaggart. He presents a second version called sophisticated McTaggart that is designed to evade an objection that I will not press. I believe I do not over-simplify by ignoring the epicycle that leads to sophisticated McTaggart.
}

Manuscrito - Rev. Int. Fil. Campinas, v. 39, n. 4, pp. 75-99, out.dez. 2016. 
that there are a series of alternatives to denying that time (or tense) is real and that one particular alternative, fragmentalism, should be given serious consideration.

The first premise of Fine's argument is

Realism Reality is constituted (at least, in part) by tensed facts. (271)

Two comments are in order, beginning with his invocation of reality.

First, Fine (262) begins with a distinction between "mere" reality and "metaphysical" reality. In Fine (2001, 2-3) he presents the same distinction this way:

Is there room for... another account of philosophy's pretensions... that does not put them in conflict with received opinion? If there is, then it requires that we be able consistently to affirm that something is the case and yet deny that it really is the case. It requires, in other words, a metaphysical conception of reality, one that enables us to distinguish, within the sphere of what is the case, between what is really the case and what is only apparently the case.

When invoking this distinction, I will usually use the more common contrast (appearance versus reality) that Fine just used, but I note that Fine prefers and usually uses his own terminology (mere versus metaphysical reality).

As one might expect, parcelling the world up into reality as opposed to appearance is not a simple or straightforward task, though Fine uses a simple example to illustrate the complex kind of thing he is getting at. Suppose someone were to tell us that Jack and Jill are a married couple. We might come to believe that in addition to the individuals Jack and Jill there is (in reality) some other thing called a couple. This belief would be mistaken, metaphysically mistaken. There is (in reality) no additional thing, a couple, in addition to Jack and Jill.

While this particular case is perspicuous, in general such a sorting (or the result of such a sorting) of propositions into those that reflect the real and those that do not is called a world-view (Fine, 28), and a world-view is the result of complex metaphysical insight and argumentation. The key point for my purposes in this paper is that, as emphasized by Fine, a statement might well

Manuscrito - Rev. Int. Fil. Campinas, v. 39, n. 4, pp. 75-99, out.-dez. 2016. 
be true but all the same misleading as to the underlying metaphysics. Jack and Jill are indeed a married couple, even though (or even if) in reality there is no such thing as a couple. ${ }^{3}$

Similarly, it may be the case that tensed statements like 'I am sitting' and 'I am standing' are (from time to time) true. They may lead one to believe in the existence (in reality) of the corresponding tensed facts. The premise of Realism above says that this conclusion is not a metaphysical mistake. The appearances in this case, if Realism is correct, happily accord with (metaphysical) reality. But this conclusion will follow only from metaphysical argument. It does not follow in any direct or straightforward way from the truth (from time to time) of tensed statements like 'I am sitting' and 'I am standing'.

Having now to some degree clarified reality, my second comment is that the previous examples do most of the work that's done in Fine's papers to clarify the notion of a tensed fact. Tensed facts make tensed statements like 'I am sitting' and 'I am standing' true (in the circumstances in which they are true) and false (in the circumstances in which they are false). As Fine points out, it is uncontroversial that there are tensed statements like 'I am sitting' and 'I am standing'. Believers and skeptics concerning tensed facts agree that we make such statements and that from time to time some such statements are true. Disagreement arises only with respect to the metaphysical theses that such statements either directly reflect or are grounded in some element of reality, tensed facts. If there are really tensed facts (possibly in addition to tenseless facts, possibly in place of them), then Fine says that reality itself is tensed. (299)

Agreement as to appearance can mask an important disagreement about reality.

Consider the issue dividing the "A-theorist" and the "B-theorist" as to whether temporal reality is intrinsically tensed. This is an issue that cannot be rendered intelligible without invoking a metaphysical

\footnotetext{
${ }^{3}$ Of course Fine (2001) has much more to say about appearance, reality, factuality, and grounding. I have tried to sketch here only the bare minimum needed to present his neo-McTaggartian argument accurately. For criticism of Fine's views see Horwich (2007) and Hofweber (2009). For Fine's replies and restatement, see Fine (2007) and (2009).
}

Manuscrito-Rev. Int. Fil. Campinas, v. 39, n. 4, pp. 75- 99, out.dez. 2016. 
conception of "fact." For the A-theorist will want to affirm, and the B-theorist to deny, that there are tensed facts in the world; and it is only the metaphysical rather than the ordinary notion of "fact" that can properly serve to represent what is here at issue. $(2001,13)$

Given the generally acknowledged importance of this issue, one might be puzzled that Fine says very little in defence of Realism. There are, after all, philosophers like Mellor [1998] who argue in elaborate, and to my mind compelling, detail that (in Fine's terms) tensed facts belong solely to the realm of appearance. We all do use tensed sentences like 'I am sitting' and 'I am standing', and we regard them as sometimes true and sometimes false. Nevertheless, in Mellor's view the underlying reality is what Fine calls tenseless facts--facts like I am sitting at time $t$ and $I$ am standing at time $t^{*}$. For the moment, let me merely note that Fine seems to think that a view like Mellor's is just not on. At one point he remarks:

But the fragmentalist, like all realists about tense, is animated by a robust sense of the inviolably tensed character of the facts. $(2005,282)$

I will return to this point below, when we can evaluate it in a wider context and see that Fine's basic argument is conditional in nature. For now one can just note that even the most vivid appearance may still be mere appearance only. Fine's own metaontological views leave it open that the underlying reality may be quite different from the way it appears and may lack tensed facts entirely.

The second premise of Fine's argument is

Neutrality No time is privileged. The tensed facts that constitute reality are not oriented towards one time as opposed to another. (271)

In particular, Neutrality rules out any metaphysical account of time (like presentism ${ }^{4}$ ) in which the present has a special role.

\footnotetext{
${ }^{4}$ Fine's own use of the term presentism (e.g., on pp. 298-99) seems to be broader than the one common in the literature, encompassing any metaphysical view, like the socalled growing block view, that gives a special role or place to the present.
}

Manuscrito - Rev. Int. Fil. Campinas, v. 39, n. 4, pp. 75-99, out.der. 2016. 
The third premise of Fine's argument is

Absolutism The constitution of reality is an absolute matter, i.e., not relative to a time or other form of temporal standpoint. (271)

This premise merits several comments. First, I will follow Fine's usage and say that some, though not all, facts constitute reality. I take this expression to mean that the those facts are constituents of reality, and that in turn entails, as we will soon see below, that the facts obtain at some time or other.

Second, Fine confronts various potential ambiguities head-on. ${ }^{5}$

For the purposes of the argument, the absolute notion of constitution that figures in the other assumptions can be taken to be either tensed or tenseless. Thus in saying that a given fact constitutes reality, one can either be speaking about the present constitution of reality or about its eternal composition. $(271)^{6}$

This distinction between tensed versus tenseless constitution, (or present versus permanent constitution), leads to another useful distinction. "Suppose," writes Fine later in the chapter, "that the realist asserts that reality is composed of different facts at different times." (273). We know (now) that realists (those who accept the first premise of Fine's argument) might be using a tensed or a tenseless notion of composition. That is, when realists say that the constitution of reality changes from time to time, they might intend that the sentence 'The tensed fact $f$ constitutes reality' is (or at least can be) true at some times and false at other times. In this case, the verb 'constitutes' is tensed, and the kind of change in the constitution of reality indicated Fine calls external change.

On the other hand, if the verb in 'The tensed fact $f$ constitutes reality' is tenseless, then that statement is always true or always false. Of course, the fact $f$ will in general obtain at some time $t$ and not obtain at some other time

\footnotetext{
${ }^{5}$ It would be more accurate linguistically to say that the expressions at issue are polysemous rather than ambiguous.

${ }^{6} \mathrm{By}$ 'eternal' I will assume Fine to mean at all times or sempiternal.
}

Manuscrito - Rev. Int. Fil. Campinas, v. 39, n. 4, pp. 75-99, out.-dez. 2016. 
$t^{*}$. Reality can change or be variegated in this way, even if there is no external change. This kind of change Fine calls internal change.

Similarly, Fine later (280) distinguishes between external and internal relativism. The former is relativism with respect to a reality that is changing externally, while the later is relativism with respect to a reality that changes only internally.

Absolutism is intended to rule out external change but not internal change, mere variegation. He makes this point clear in the following explanation:

If Absolutism is rejected, then one obtains a form of relativism. But this is not relativism of the usual sort, for it is not the facts themselves that are relative but the very constitution of reality. The facts themselves may well be absolute; they may include the unadorned fact that I am sitting, for example, or the unadorned fact that I am standing. But their belonging to reality will be a relative matter. Thus reality will not be absolutely constituted by the fact that I am standing, but only relative to a given time. $(2006,401)$

Finally, the fourth Premise of Fine's argument is

Coherence Reality is not contradictory. It is not constituted by facts with incompatible content. (271)

Tensed facts that cannot be true at the same time have incompatible content. For instance, the tensed facts $I$ am sitting and I am standing have incompatible content. (282) If reality is constituted by both tensed facts (as it seems to be), then it is not coherent in the sense of the fourth premise.

Why are these four premises inconsistent? It is worth quoting Fine's pithy argument:

[] $\mathrm{t}$ follows from Realism that reality is constituted by some tensed fact. There will therefore be some time $t$ at which this fact obtains. Now Neutrality states that reality is not oriented towards one time as opposed to another. So reality will presumably be constituted by similar sorts of tensed facts that obtain at other times. But this means, as long as temporal reality is sufficiently variegated, that some of these facts will have incompatible contents. If reality is constituted by the present fact that I am sitting, for example, then it may well be constituted by the subsequent fact that I am standing. By Absolutism,

Manuscrito - Rev. Int. Fil. Campinas, v. 39, n. 4, pp. 75-99, out.dez. 2016. 
reality is absolutely constituted by such facts; and this is then contrary to Coherence (and the underlying assumption of Absolutism). (2006, 400)

It is worth noting that there are other assumptions used above than the four that appear officially as premises in Fine's neo-McTaggartian argument. ${ }^{7}$ One is that reality is sufficiently varied (internally, if Absolutism is to be maintained) that there are tensed facts with incompatible content. If one grants the assumption that there are tensed facts at all (Realism), it is not difficult to grant the further assumption of internal variegation.

Another is the relation between tensed facts and "times" implicit in the use of 'therefore' in the quote above. If a tensed fact constitutes (is some part of, is a constituent of reality, then there is some time $t$ at which that tensed fact obtains. Since I have never sailed and presumably never will sail, the tensed fact $I$ am sailing does not constitute reality. The tensed facts I am sitting and $I$ am standing do constitute reality.

One must be careful, Fine warns us, to distinguish the entailment just indicated from the idea that for reality to be constituted by some tensed fact such as I am sitting is for there to be some time $t$ at which the tenseless fact $I$ am sitting at $t$ obtains (in reality). (271-2) This way of construing constitution, according to Fine, is a bait-and-switch operation, appearing to sell us tensed facts but delivering a reality constituted only by tenseless facts. If one fell for it,

The assumption of Realism would then hold but not in its intended sense, since reality's being constituted by a tensed fact would amount to no more than its being constituted by a corresponding tenseless fact. (271)

This warning later reappears as a kind of methodological rule, called No Collapse, that the Realist's position must not be elaborated in such a way that it collapses into anti-realism--that is, into a position in which tensed facts are replaced by tenseless facts. (273-4) For Fine, such a "realist" is a sheep in wolf's clothing.

${ }^{7}$ Correia and Rosenkranz (2012) exploited this fact to clear conceptual space for a neutral realist option not examined by Fine that they call dynamic absolutism.

Manuscrito - Rev. Int. Fil. Campinas, v. 39, n. 4, pp. 75-99, out.-dez. 2016. 
We now have in place, I believe, a statement of the neo-McTaggartian argument and some brief explanation of its key concepts, as Fine understands them. Let us now turn to the use he makes of this argument.

\section{Neutral Realism}

In Fine's view McTaggart style arguments have been used to cast doubt upon Realism. He wants to turn the tables. Having unearthed the major premises in his version of the argument, he would like to explore the space of views that include Realism but then accordingly deny at least one of the three other premises, since the four premises together are inconsistent. Realism itself, then, by design goes largely unexamined in the unfolding of this dialectic. If, as I think, it turns out that none of the views that include Realism is satisfactory, then the upshot of the neo-Mctaggartian argument is no more favourable to Realism than the original McTaggart argument.

Fine's first step is to ask whether Realists should endorse Neutrality. Most realists do not, and he labels this lot the standard realists. Presentists are paradigmatic standard realists. Quite naturally he calls those who do attempt to combine Neutrality with Realism non-standard realists, but I find this terminology awkward. I will instead call them neutral realists, a term Fine himself uses from time to time (e.g., 286).

Fine then offers three arguments that are intended to convince the reader that neutral realism is superior to standard realism, even though standard realism has the advantage of evading the neo-McTaggartian argument in what seems a natural fashion. The first argument for the superiority of neutral realism (in $\$ 7$ of his paper) is the argument from passage, then the argument from truth (in $\$ \int 8-9$ ), and finally (in $\$ 10$ ) the argument from special relativity. I will examine these three arguments in turn in this section and the two following.

Passage, Fine tells us, provides "the original motivation for the realist view." (286) Time is in some way quite different from space. It passes or lapses, while space does not. But what is this passage and how, if at all, can a metaphysician account for it?

Fine quotes approvingly a famous characterization of passage by Kurt Gödel (1949b, 558): “The existence of an objective lapse of time, however,

Manuscrito - Rev. Int. Fil. Campinas, v. 39, n. 4, pp. 75-99, out.dez. 2016. 
means (or is at least equivalent to the fact) that reality consists of an infinity of layers of "now' which come into existence successively." Layers of "now" are global sets of simultaneous (or more generally acbronal) point events. Passage is the successive occurrence (or "coming into existence") of such sets of events. At least, this is the pre-relativistic picture of passage. ${ }^{8}$ I will follow Fine in assuming that accommodating in some way this picture of passage is "the original motivation for the realist view."

Fine thinks that standard realists cannot accommodate passage in their metaphysics.

The standard realist faces a general difficulty. For suppose we ask: given a complete tenseless description of reality, then what does he need to add to the description to render it complete by his own lights? The answer is that he need add nothing beyond the fact that a given time $t$ is present, since everything else of tense-theoretic interest will follow from this fact and the tenseless facts. But then how could this solitary 'dynamic' fact, in addition to the static facts that the anti-realist is willing to accept, be sufficient to account for the passage of time? (287)

This is an interesting (surprising, even) argument in general, but in the dialectical context of Fine's paper it is extremely puzzling. Fine seems to allow standard realists to start with a structure known to fans of McTaggart (1908) as the B-series or to students of Howard Stein (1967) as Newtonian spacetime or to readers of Robert Geroch (1978) as Aristotelian spacetime9--sets of simultaneously obtaining facts (in Fine's preferred way of speaking) or simultaneously occurring events (in my preferred way of speaking) completely

8 We will discuss relativity below in the context of the third argument.

"Geroch's description of what he calls "Aristotelian spacetime" is extraordinarily perspicuous, especially for those not immersed in spacetime jargon. It is not, however, a description of spacetime (or space and time) as Aristotle imagined them. It is Newton's spacetime (or space and time). I will below drop the use of Geroch's label, even though his account may prove useful to many readers.

Manuscrito - Rev. Int. Fil. Campinas, v. 39, n. 4, pp. 75-99, out.dez. 2016. 
ordered by the transitive and asymmetric relation is later than. This is what I take a "complete tenseless description of reality" to be. ${ }^{10}$

To this structure, Fine allows standard realists to add the distinctive element of their view, a property of being present or now. One time is special or distinguished in virtue of having this property. Does this structure of ordered sets with one of them marked out as special look dynamic? No, Fine says, it does not.

" $[\mathrm{H}]$ ow can the passage of time be seen to rest on the fact that a given time is present and that various other times are either earlier or later than that time?.... Even if presentness is allowed to shed its light upon the world, there is nothing in his metaphysics to prevent that light from being 'frozen' on a particular moment of time.” (287)

This argument is striking, since standard realists pride themselves on being the very metaphysicians that take passage seriously. If Fine's argument is correct, they are not. But to return to the larger context of this argument, the argument from passage is supposed to show that neutral realism is superior to standard realism - presumably by its accounting for passage while standard realism cannot; but Fine does not explicitly argue that neutral realism can do what he says standard realism cannot. In fact, if neutral realists are required to start from the same point as standard realists--from a complete tenseless description of reality--but lack one element that standard realists have (a distinguished present, perhaps, or a spotlight illuminating some time slice), it is hard to see how they could succeed where standard realists fail.

But perhaps, as Fine pointed out to $\mathrm{me}^{11}$, one should view neutral realists not as lacking a tool that standard realists have, but as having more freedom with it. Rather than being restricted to designating one special time as now or present, and so risking being saddled with one "frozen" present like standard realists, neutral realists can hold that, corresponding to each time t, there is (in

${ }^{10}$ To avoid being misunderstood, let me indicate that this description is complete in the sense that it says everything that one can say tenselessly. Whether this description is complete in the sense of describing all temporal reality is one way of putting the question that divides (so-called) A-theorists from (so-called) B-theorists. (See Pooley, 2013.) Fine is certainly not presupposing the truth of the B-theory.

${ }^{11}$ In correspondence.

Manuscrito - Rev. Int. Fil. Campinas, v. 39, n. 4, pp. 75-99, out.dez. 2016. 
reality) the tensed fact that $\mathrm{t}$ is now or present. In this way neutral realists ensure the reality of all the successive nows, all the nows that were, or are, or will be.

The "times" $\mathrm{t}$ are, as I understand the proposal, sets of simultaneously obtaining facts or simultaneously occurring events in the B-series or Newtonian spacetime, as noted above. These sets of facts or events form a structure, which may be indicated by $\mathrm{E}^{3} \times \mathrm{R}$, the Cartesian product of threedimensional Euclidean space with the real line. The tensed facts, of the form $t$ is now, if they are to ensure the reality of the successive nows or presents, must themselves obtain or occur successively and so must also have the structure of the real line. ${ }^{12}$ They are not to be thought of as a totum simul.

In fact, if no two distinct times can both be now or present simultaneously, as I think Fine believes, then he cannot be proposing a totum simul. But it is useful to note that if no two distinct times can both be now or present simultaneously, then the tensed facts indicating their presentness or nowness are pairwise inconsistent. That is, if all these tensed facts constitute reality (by Absolutism, premise 3 above), then reality is massively incoherent (that is, in violation of premise 4 above). I think we have here our first, and perhaps our best, insight into the nature of fragmentalism, the view we are left with should we abandon premise 4 of the neo-McTaggartian argument.

We have thus arrived at a crossroads, possibly the most fundamental crossroads in the philosophy of time. One view is that the B-series or Newtonian spacetime (often referred to as the block universe) is static, inert. The structure $\mathrm{E}^{3} \times \mathrm{R}$ may adequately represent the geometry of space, it is often said, but not the dynamic or transitory aspect of time. Since time strikingly has a dynamic or transitory aspect, Fine (as neutral realist) adds the set of tensed facts of the form $t$ is now or $t$ is present. The totality of these facts straightforwardly duplicates the temporal structure of the B-series, to which it is isomorphic. In some way this second structure is supposed to add the lacking dynamical quality to reality that the first alone lacks.

While there is almost an irresistible pull in the direction of duplication, there are those who nevertheless resist. Is the invocation of a second temporal structure or dimension coherent? Is it helpful? Is it needed? I have argued

\footnotetext{
${ }^{12}$ The set of times need not be dense; but that is the usual assumption, and I assume it here for convenience. No issue of importance for the arguments discussed in this paper depends on it.
}

Manuscrito - Rev. Int. Fil. Campinas, v. 39, n. 4, pp. 75-99, out.-dez. 2016. 
elsewhere (Savitt 2002) that this duplication is not needed. What I will try to argue here, in presenting Fine's arguments, is that it is not helpful in forming a picture of a fully dynamic time. Leaving the persuasive labels (tensed vs tenseless) aside, I ask: what is more (or less) dynamic in the set of tensed facts or events like $t$ is present ordered by the is later than relation than is to be found in the sets of simultaneous tenseless facts or events ordered in the same way (successively) by the same relation? Nothing, I submit. ${ }^{13}$

Nor, I further suggest, is there a clear advantage of either of these two views over anti-realism when it comes to providing an account of passage. To many the structure of the tenseless facts, the B-series or Newtonian spacetime, has looked "static". It is true that the picture standardly used to illustrate the B-series or Newtonian spacetime is static; but what this picture depicts is the history of a universe unfolding in time. A static picture can represent a dynamically unfolding universe, just as a two-dimensional figure can represent a three-dimensional object. ${ }^{14}$ If this is so, then Newtonian spacetime or the B-series needs no duplication.

At the end of Fine's first argument, then, we find that a consideration of passage not only provides no reason that neutral realism is preferable to standard realism but also that it provides no reason to suppose that either view is preferable to anti-realism.

\section{Truth and Relativity Theory}

The second argument is the argument from truth. Here is Fine's account of its point:

${ }^{13}$ Jonathan Tallant [2013] also argues that Fine's argument from passage fails to show that neutral realism is superior to standard realism. Tallant criticizes Fine from a point of view that he calls existence presentism and that Fine (I think) would classify as standard realism + external relativism. I differ from Tallant by not embracing realism, but he agrees with me in aiming for a minimalist understanding of passage. It should be clear that I believe that a minimalist understanding of passage renders tensed facts otiose. ${ }^{14}$ For an elaboration of this idea see Savitt [2002].

Manuscrito - Rev. Int. Fil. Campinas, v. 39, n. 4, pp. 75-99, out.-dez. 2016. 
The present argument is to the effect that the realist is unable to provide a reasonable account of the connection between the truth of tensed utterances and the tensed character of reality. If, as I attempt to show in the next section, it is only effective against the standard realist, then it provides another indirect argument in favour of the nonstandard view. (288)

The argument from truth is intricate, and I do not wish to consider it in detail here. ${ }^{15} \mathrm{I}$ hope that it will suffice to make just a few observations concerning it.

The argument from truth is prima facie intended to be a reductio ad absurdum of realism:

We may state the objection in the form of an argument from certain assumptions which it seems clear the realist must accept. It may then be shown that these assumptions lead to a contradiction and that the realist position should therefore be abandoned. $(2006,406)$

After laying out the full argument, Fine notes that neutral realists are able to replace one of the premises of the argument

Link An utterance is true if and only if what it states is verified by the FACTS,

where the capitalized 'FACTS' is meant to indicate what is true in reality, with a weaker premise

Relative Link. An utterance is true if and only if it states what is verified by the FACTS that obtain at the time of utterance. $(2006,409)$

Since, presumably, the standard realist "must" accept Link (along with the rest of the argument that leads to contradiction), Fine wishes us to conclude that standard realism is an an untenable view, whereas neutral realism, which can adopt Relative Link and so escape the reductio, is at least a live option.

\footnotetext{
15 Tallant (2013) does consider the argument in detail. He too thinks it fails, though for reasons that differ somewhat from mine.
}

Manuscrito - Rev. Int. Fil. Campinas, v. 39, n. 4, pp. 75- 99, out.-dez. 2016. 
Having sketched the general form of the argument, I turn to two of the premises that realists in general "must" accept. The premises are

Truth-value Stability If it is correct to assert that a given utterance is true (false) at one time, then it is correct to assert this at any later time,

and

Content Stability If it is correct to assert that an utterance states that such and such at one time, then it [is] correct to assert this at any later time. $(2006,407)$

There is a possible ambiguity in these premises. If we focus on the 'this' in Truth-value Stability, for instance, we see that the premise could be understood in either of two ways.

(1) Consider an assertion (a token of some type utterance) U1 made at a time $t_{1}$. Truth-value stability might be understood to require that another token of this type, $\mathrm{U} 2$, uttered at $\mathrm{t}_{2}$, have the same truth value as the token uttered at $t_{1}$. (I will call this the strong reading of the premise). (2) Truth-value stability might, however, be understood to assert merely that, if the token $\mathrm{U} 1$ is true (or false) at $t$, then at any later time $\mathrm{t}_{2}$ it remains true to assert that the token $\mathrm{U} 1$ was true (or false) at $t_{1}$. (I will call this the weak reading of the premise.)

The first point to note is that Fine can not intend what I call the strong readings of both Truth-value Stability and (mutatis mutandis) Content Stability. A sentence type whose tokens conform to these two principles (read along the lines of (1) above) is a tenseless sentence type. ${ }^{16}$ The sentence type used by Fine in the argument from truth is 'I am sitting'. No realist (and no antirealist either, for that matter) would regard this as a tenseless type. That is, on the first or strong readings no realist need be (or even can coherently be)

${ }^{16}$ For a particularly clear statement of this uncontroversial distinction, see pages 7-8 of Markosian (1992).

Manuscrito - Rev. Int. Fil. Campinas, v. 39, n. 4, pp. 75-99, out.der. 2016. 
committed to both premises if they are meant to apply to the sort of sentence type Fine uses in his example. ${ }^{17}$

But on the second or weak readings, even were realists required to embrace these two premises, no contradiction is evident. Suppose that at $\mathrm{t}_{1}$ one utters, truly, 'I am sitting' (U1). At $\mathrm{t}_{2}$, if one utters U2, a second token of 'I am sitting', it is quite consistent to say (as Fine requires) that U2 is false and (as the weak reading of Truth-value Stability permits) that U1 was true (at $\mathrm{t}_{1}$ ) or even, given the vagaries of ordinary language, that $\mathrm{U} 1$ is true.

If any hint of contradiction emerges, I claim that it is a result of a natural tendency to understand Truth-value Stability and Content Stability in the (unavailable) first or stronger" ways. Fine says, for instance, that "by Truthvalue stability, it is correct to assert at $\mathrm{t}_{2}$ that $\mathrm{U} 1$ is true" $(2006,408)$, whereas my claim is that all he is entitled to assert from his premises without further argument is that at $\mathrm{t}_{2} \mathrm{U} 1$ was true.

Perhaps a contradiction can be generated when we add, as Fine supposes,

Link An utterance is true if and only if what it states is verified by the FACTS;

but if so, I claim that we are still owed an argument from this point to a contradiction.

Nor is Link required of realists, even if they are inclined towards truthmaker principles. Ulrich Meyer $(2013,55)$ wrote that "truth supervenes on how things were, are, and will be, and that is all that can or needs to be said about this." I agree. If Meyer's view suffices, ${ }^{18}$ then it is up to Fine to finish his reductio from it (or, perhaps, from Link) and from the other premises, rendered without ambiguity. I conclude then that as it stands, the argument from truth constitutes no reductio and so it provides no reason to favour

\footnotetext{
${ }^{17}$ Fine does seem to reject the strong readings in his discussion on pp. 292-294, as the editor of this issue pointed out to me.

${ }^{18}$ Link seems to leave open that there are FACTS involving abstract entities that are in some way non-temporal, but these FACTS do not seem relevant in a discussion of time and tense. The remaining FACTS are temporal, and so either were, are, or will be.
}

Manuscrito - Rev. Int. Fil. Campinas, v. 39, n. 4, pp. 75- 99, out.dez. 2016. 
neutral realism over standard realism or to favour any sort of realism over anti-realism.

\section{Special Relativity and Fragmentalism}

Let us move on then to the third argument, the argument from the special theory of relativity. This argument is, in a way, transitional. In addition to wrapping up Fine's case for the superiority of neutral realism to standard realism, it opens the campaign to show that fragmentalism is superior to relativism. We will consider, then, both facets of this argument.

Standard realists (or presentists) confronting the special theory of relativity are offered two ways to construe the present. The first is to take the present as a hypersurface of simultaneity relative to an inertial frame. But since any point in Minkowski spacetime is contained in a non-denumerable infinity of inertial world lines, there are a non-denumerable infinity of such presents (hyperplanes orthogonal to these inertial world lines) at each point. They cannot all be what Fine calls "the standpoint of reality." If one were to choose arbitrarily one of these hypersurfaces as the present, as the standpoint of reality, then one would have an "absolute" (that is, frame-independent) simultaneity, and this (Fine rightly observes) is inconsistent with the special theory. (See $\$ 7$ of Pooley, 2013, for further argument to this point.)

A second way to construe the present is as a spacetime point, the herenow (Stein, 1967). Each spacetime point or event would be its own present. But understanding the present this way, the locational view, abandons the fundamental metaphysical motivation for standard realism. Here is how Fine sees it:

One of the primary motivations for the presentist view [standard realism] is that it enables one to distinguish between space and time. Temporal indexicality is metaphysically significant, while spatial indexicality is not; there is an objective 'now', even though there is no objective 'here'. However, once we adopt the locational view, this asymmetry between space and time disappears. The two forms of indexicality collapse one into the other and reality can no more be said to be oriented towards a temporal standpoint than towards a spatial standpoint; the 'here' is as objective as the 'now'.

Manuscrito - Rev. Int. Fil. Campinas, v. 39, n. 4, pp. 75-99, out.dez. 2016. 
If these are the difficulties confronting standard realism, can neutral realism do better? That is, given the constraints of Fine's neo-McTaggartian argument and a reluctance to view time as relative, can fragmentalism do better?

Reality, for the fragmentalist, is a mosaic--the bits and pieces of the picture being maximal coherent sets of tensed facts. Fine says little about the relation of coherence, ${ }^{19}$ so I suggest we start with the grand vision of fragmentalism (viz-a-viz the special theory of relativity) and then try to work out details.

The resulting metaphysical view is quite remarkable. The usual view is that SR shows space-time to be Minkowskian rather than Newtonian; physical processes are to be seen as taking place within a physical space-time with the structure of Minkowskian rather than Newtonian space-time. But the present view is that what SR shows to be mistaken is not that space-time is Newtonian but that there is a single spacetime. Thus we should picture physical processes as taking place within a plurality of physical space-times, each of them enjoying a common ontology of space-time locations and each of them Newtonian in structure, and yet differing in the spatial and temporal relationships that hold among the space-time locations. (306)

Let us label the "common ontology of space-time locations" Cr. It is usual in the special theory to refer to the locations in $\mathrm{C}$ a as events- $\mathrm{e}_{0}, \mathrm{e}_{1}, \mathrm{e}_{2}$, etc. These events are point events; they are instantaneous and lack extension (as Minkowski spacetime is usually understood). What are the tensed facts that inhabit or?

Before [that is, when thinking pre-relativistically], the fact that a given event was present was taken to be absolute and capable of belonging to reality, notwithstanding its relativity to a time. Similarly, the fact that two events are simultaneous is now taken to be absolute and capable of belonging to reality, notwithstanding its relativity to a frame. Finally, in order to avoid privileging one time over another, we took the facts that a given event was present, past, and future to be equally capable of belonging to reality (whether to a fragmented reality or to one that is indexed to a time). Now, in order to avoid privileging one frame over another, we take the facts that two events are simultaneous or

${ }^{19}$ Lipman [2015], on the other hand, treats coherence in detail.

Manuscrito - Rev. Int. Fil. Campinas, v. 39, n. 4, pp. 75-99, out.dez. 2016. 
that either one is earlier than the other to be equally capable of belonging to reality (which, again, is either fragmented or indexed to a frame-time).

What is unequivocal in the above quotation is that, from the standpoint of special relativity, the tensed facts are taken to be facts of the form $e_{1}$ is simultaneous with $e_{2}$ and $e_{1}$ is earlier than $e_{2}$. Fine thinks that facts like these constitute reality, as described in section I above, and in that sense are "absolute".

We can suppose that fragmentalists are able to understand the postulates of the special theory of relativity and their implications and so can, with suitable effort, distinguish pairs of points that are spacelike, timelike and lightlike separated. Then they can distinguish straight (inertial) timelike lines, can construct inertial frames, and evaluate facts like $e_{1}$ is simultaneous with $e_{2}$ and $e_{1}$ is earlier than $e_{2}$ relative to these frames. The upshot is this: in each frame $F$ the relation $e_{i}$ is simultaneous with $e_{j}$ (where the two events are spacelike separated) is an equivalence relation and the equivalence classes under this relation are ordered by the relation $e_{i}$ is earlier than $e_{j}$ (when $e_{i}$ and $e j$ are timelike separated and are taken to be representative events in their respective equivalence classes).

In this picture each of the continuum-many frames is, as described in $\$ 2$ above, a B-series or a Newtonian spacetime. We have recovered, then, the grand vision of fragmentalism decribed by Fine at the beginning of this section.

This vision is quite conservative, emphasizing as it does the traditional, familiar Newtonian structure of spacetime as opposed to the novel and (to most) unintuitive but (to others) quite elegant geometric structure of Minkowski spacetime.

But Fine, as we saw at the beginning of this paper, describes his idea as "radically new." What, one might then ask, is new about it? Philosophers have tried for decades to save our familiar "folk" or Newtonian notions of time from the menace of relativity (See Zimmerman [2011] for an extended discussion of these efforts.), but these are the standard realists. They are bent upon preserving one particular hyperplane of simultaneity as the present and one particular frame in which the usual notions of tense (past, present, and future) are "objective." What is novel in Fine's fragmentalism, it seems to me, is that it abandons any attempt to single out as "privileged" one inertial frame

Manuscrito - Rev. Int. Fil. Campinas, v. 39, n. 4, pp. 75-99, out.dez. 2016. 
amongst the many. If inertial frames are the fragments of Fine's fragmentalism, then they are all equally bits of the mosaic.

Whether inertial frames are fragments depends upon what sorts of facts there are, ${ }^{20}$ and that in turn depends at least in part on how fragmentalists wish to account for the passage of time. Suppose, for example, that they wished to adopt the minimalist account of (pre-relativistic) passage I proffer in Savitt [2002]. Passage is, on that view, just the successive occurrence of sets of simultaneous events. The events in $\mathrm{C} / \mathrm{are}$ already partitioned into these sets and the sets are already ordered in the various frames. No facts need be added to the ones already required-facts like $e_{1}$ is simultaneous with $e_{2}$ and $e_{1}$ is earlier than $e_{2}$. In this case, I suspect that all such facts relative to a frame cohere (and cohere in way that KF is sitting and KF is standing did not in the earlier discussion of pre-relativistic time).

Fragmentalists might find some version of the moving spotlight view attractive. In that case, they would require facts like $e$ is present, $e$ is past (or future), or perhaps $e$ is past ${ }_{n}$ (or future $e_{n}$ ), where $\mathrm{n}$ indicates by how many time units the event is past or future. These facts represent the fleeting adherence of properties like '_ is present' in events. In this case, the frame-times (the sets of events in each frame with the same time coordinate, given some standard way of assigning coordinates to events in $\mathrm{Cr}$ ) look to be the maximally coherent sets of facts.

Or fragmentalists might live fully up to their name by following Earman [2008] and chipping the whole frame (or block) into continuum-many pieces of increasing volume, each piece beginning at some one initial time or at no initial time but all ending at different times. This is a version of the growing block view, and I will leave it to others to decide whether the frames or their pared-down blocks (or perhaps something else) are the fragments.

The difficulty with each of these proposals is easily seen in the mere statement of their purpose - to account for the passage of time. Each proposal yields a multiplicity of passages rather than the sought-for unique unfolding of the universe. The second proposal, for instance, provides us with a nondenumerable infinity of distinct moving spotlights with no physical test or system being able to pick out one of them as representing the passage of time. I by no means wish to insist on uniqueness as a necessary condition for a

${ }^{20}$ A fragment is a "maximally coherent collection of facts".

Manuscrito - Rev. Int. Fil. Campinas, v. 39, n. 4, pp. 75- 99, out.dez. 2016. 
proper account of the passage of time, but I believe that the proponents of the traditional views just sketched will be unsettled by such multiplicity.

Another difficulty is that it does not seem that the fragmentalist's picture underwrites a metaphysical distinction between the here and the the now that was, supposedly, lacking in the locational view. What is now is still relative to one's choice of inertial frame and some event in that frame. It is all the events that have the same time coordinate (conventionally, 0 ) as the chosen event. But the events that are here are all the events that have the same three spatial coordinates (conventionally $(0,0,0)$ ) as the chosen event, and that equally depends on one's choice of frame and event. Where is the metaphysical distinction?

Such is the unusual picture needed, according to Fine, to preserve Realism. When I criticized the conclusion Fine drew from the argument from passage above in section II, I claimed that the structure of tensed facts that he claimed to exist unnecessarily duplicated the structure of the underlying Newtonian spacetime. I cannot make such a claim here. The structure of the underlying spacetime is Minkowskian, while the structure of each fragment is Newtonian. But while there is no straightforward duplication of structures, there is a remarkable proliferation of fragments. One spacetime is replaced (or augmented?) by a non-denumerable infinity of fragments. If we take Fine at his word, that each fragment is an element of metaphysical reality, the fragmentalist's vision is every bit as ontologically extravagant as the many worlds in the Everett interpretation of quantum mechanics or the multiverse of eternal inflation cosmology. The latter two views are, however, motivated (though not, of course, mandated) by serious physical theories. Fragmentalism appears to be motivated by a desire to save, but perhaps in an etiolated form, a traditional metaphysics of time. Fragmentalism is not logically inconsistent or incoherent, but it seems too high an ontological price to pay for whatever small rewards it may deliver.

Let me emphasize just how small the rewards are. One motivation for fragmentalism is, as mentioned, the preservation of a traditional metaphysics of time, allowing one to tell a story (in fact, many stories, or perhaps one story from many viewpoints) of the temporal unfolding of the universe as a whole. It is worth noting that this advantage runs into a serious difficulty in the general theory of relativity.

Manuscrito - Rev. Int. Fil. Campinas, v. 39, n. 4, pp. 75-99, out.dez. 2016. 
One can make the notion of temporal unfolding precise by using a global time function. A global time function $\mathrm{t}$ assigns times (real numbers) to events in such a way that when event $\mathrm{e}_{1}$ causally precedes event $\mathrm{e}_{2},{ }^{21}$ then the time assigned to $\mathrm{e}_{1}$ (that is, $\mathrm{t}\left(\mathrm{e}_{1}\right)$ ) is less than the time assigned to $\mathrm{e}_{2}, \mathrm{t}\left(\mathrm{e}_{2}\right)$. If one collects into sets all the events that occur at $t\left(\mathrm{e}_{1}\right), \mathrm{t}\left(\mathrm{e}_{2}\right)$, and so on, then these sets are the global time slices needed for a coherent evolution of the universe from earlier to later times.

Gödel [1949a] showed that there was a general relativistic spacetime (that is, a spacetime the equations of which are an exact solution of the Einstein field equations) in which there is no global time function. If such a function is a necessary condition for there to be passing or lapsing time, then in that universe time demonstrably does not pass or lapse.

John Manchak [2016] has recently proved the remarkable result that, as long as our knowledge of the universe is confined to our past light cone (that is, to information arriving at speeds no greater than that of light in vacuo), then no matter how much information we have about our universe, it is possible (that is, compatible with the laws of general relativity) that our universe has no global time function. If the passing or lapsing of time requires one, then we can never know that time passes or lapses.22 Those who think they know that time passes must either impugn the general theory of relativity (a dangerous course for a philosopher, in my view) or find a way to think about passage that does not involve global time slices.

Having reached an apparent dead-end within the structure of Fine's neoMctaggartian argument, many philosophers will be tempted to revisit the

${ }^{21}$ That is, if there is a continuous, everywhere future-directed timelike or null curve from e1 to e2.

22 A reader might note that in Savitt [1994] the argument that I presented on pages 465-468 could be construed as an argument for the following conclusion: if the existence of global time slices is a necessary condtion for there to be an objective lapsing of time (premises A1 and A2), then our experience of time as if lapsing provides no ground for believing that time does lapse (concluision B6). This argument was based on the premise that, whatever the global causal structure of our universe, locally it would look as if time objectively lapsed. Support for this premise is to be found in Wald [1984, 263]. Manchak's proof establishes that, however our universe looks here and now and for all our past, it (nomically) might be a universe in which there is no objective lapsing of time.

Manuscrito - Rev. Int. Fil. Campinas, v. 39, n. 4, pp. 75-99, out.-dez. 2016. 
decision to abandon standard realism in favour of Neutrality. I believe that there are independent arguments that this choice is at best a path into a hopeless dialectic (Dolev, 2007) or at worst embracing an illusion (Meyer (2005), Savitt (2006)). What I suggest instead is that one abandon Realism and the complexities it brings in its train. If the arguments above are correct, no metaphysical purchase on time or temporal passage will be lost.

If one abandons tensed facts, one is free to look at Minkowski spacetime in the usual way. Frames (aka fragments) fit together in a remarkably smooth way. The measured (frame-dependent) lengths and times are connected by a well-defined set of functions, the Lorentz transformations. Why? The usual answer-and, I think, the correct answer-is that the frame-dependent quantities are projections of an invariant four-dimensional quantity, the spacetime interval. ${ }^{23}$ One might well be tempted to say that frames provide "perspectives" on this unique underlying reality, despite Fine's explicit rejection of this way of looking at the matter in the quote at the beginning of this paper and in 2005, 282-3.

The usual approach to relativity does not solve the problem of accounting for passage in Minkowski spacetime, but, as I have argued, neither does Fine's. There are, however, ways that temporal evolution might be found in Minkowski spacetime given the usual approach. One might try to exploit the notion of proper time, for instance, as suggested in Stein [1967] and Savitt [2009], to develop a local notion of passage. ${ }^{24}$ One might eventually hope to find a place for such a notion, or another similarly local one, in the general theory.

${ }^{23}$ Hofweber and Lange [unpublished] argue this point quite forcefully.

24 I am grateful to Kit Fine and Martin Lipman for correcting several misunderstandings and outright mistakes in earlier versions of this paper and to Roberta Ballerin for her insightful criticism as the paper developed. Any residual mistakes are, of course, my own responsibility. It may be worth reiterating that "Fine's approach," as I use the term in this paper, means assuming Realism as a premise and then seeing what consequences follow in the context of the neo-McTaggartian argument. As far as I know, Fine nowhere unequivocally endorses Realism.

Manuscrito - Rev. Int. Fil. Campinas, v. 39, n. 4, pp. 75-99, out.-dez. 2016. 


\section{References}

CORReiA, F. and S. Rosenkranz, "Eternal Facts in an Ageing Universe," Australasian Journal of Philosophy 90 [2012]: 307-320, 2012.

Deng, N., "Fine's McTaggart, Temporal Passage, and the A versus BDebate," Ratio, 2012: doi: 10.1111/j.1467-9329.2012.00526.x.

Dolev, Y. Time and Realism: Metaphysical and Antimetaphysical Perspectives. Cambridge, MA: The MIT Press, 2007.

EARman, J. "Reassessing the Prospects for a Growing Block Model of the Universe," International Studies in the Philosophy of Science 22: 135-164, 2008.

FINE, K., “The Question of Realism,” Philosophers' Imprint 1: 1-30, 2001. "Tense and Reality" in his Modality and Tense: Philosophical Papers.

Oxford: Oxford University Press, 2005. "The Reality of Tense," Synthese 150: 399-414, 2006. "Response to Paul Horwich," Dialectica 61: 17-23, 2007. "The Question of Ontology," in Metametaphysics: New Essays on the Foundations of Ontology, eds., D. Chalmers, D. Manley, and R. Wasserman. Oxford: Oxford University Press, 2009.

Geroch, R., General Relativity from $A$ to B. Chicago and London: The University of Chicago Press, 1978.

GÖDEL, K., "An Example of a New Type of Cosmological Solutions of Einstein's

Field

Equations of Gravitation," Reviews ofModern Physics 21 [1949a]: 447-450.

Reprinted in Gödel's Collected Papers, vol. II, Feferman, S. et al. ed. "A Remark about the Relationship between Relativity Theory and Idealistic Philosophy" in P. A. Schilpp, ed., Albert Einstein: PhilosopherScientist. La Salle, Illinois: Open Court, 1949b.

Hofweber, T., "Ambitious, yet Modest, Metaphysics," in Metametaphysics: New Essays on the Foundations of Ontology, eds., D. Chalmers, D. Manley, and R. Wasserman. Oxford: Oxford University Press, 2009.

Hofweber, T. and M. Lange. "Fine's Fragmentalist Interpretation of Special Relativity," [unpublished].

HORWICH, P., "The Quest for REALITY,” Dialectica 61: 5-16, 2007.

LipMAn, M., “On Fine's Fragmentalism,” Philosopbical Studies 172: 3119-3133, 2015.

Manuscrito - Rev. Int. Fil. Campinas, v. 39, n. 4, pp. 75-99, out.-dez. 2016. 
MANCHAK, J., "On Gödel and the Ideality of Time," Philosophy of Science 83: 1050-1058, 2016.

Markosian, N., "On Language and the Passage of Time," Philosophical Studies 66: $1-26,1992$.

MeLLOR, D. H., Real Time II. London and New York: Routledge, 1998.

Meyer, U. "The Presentist's Dilemma," Philosophical Studies 122: 213-224, 2005.

The Nature of Time. Oxford: Oxford University Press, 2013.

POOLEY, O., "Relativity, the Open Future, and the Passage of Time," Proceedings of the Aristotelian Society 113, Part 3: 321-363, 2013.

SAVITT, S., "The Replacement of Time," Australasian Journal of Philosophy 72: 463-474, 1994.

, "On Absolute Becoming and the Myth of Passage," in C. Callender, ed., Time, Reality \& Experience. Cambridge: Cambridge University Press ,2002.

"Presentism and Eternalism in Perspective," in The Ontology of Spacetime, Vol 1, Dieks, D. (ed.), pp 111-127. Amsterdam, The Netherlands and Oxford, UK; Elsevier,2006 [This article was posted on the PhilSci Archive in June, 2004.]

"The Transient nows," in Quantum Reality, Relativistic Causality, and Closing the Epistemic Circle, Myrvold, W. and J. Christian (eds.) (2009); Springer: 349-362.

STEIN, H., "Newtonian Space-Time," The Texas Quarterly 10: 174-200, 1967. Stoneham, T., "Time and Truth: The Presentism-Eternalism Debate," Philosophy 84: 201-218, 2009.

Tallant, J., “A Heterodox Presentism: Kit Fine's Theory," in New Papers on the Present, Ciuni, R., K. Miller, and G. Torrengo (eds.), pp. 281-305. Munich, Philosophia Verlag GmbH., 2013.

WALD, R. General Relativity. Chicago and London, University of Chicago Press. Zimmerman, D., "Presentism and the Space-Time Manifold" in The Oxford Handbook of Philosophy of Time, Callender, C. (ed.), pp. 163-244. Oxford, Oxford University Press, 2011.

Manuscrito - Rev. Int. Fil. Campinas, v. 39, n. 4, pp. 75-99, out.-dez. 2016. 